"This document is the Accepted Manuscript version of a Published Work that appeared in final form in Journal of the American Chemical Society, copyright (C) American Chemical Society after peer review and technical editing by the publisher. To access the final edited and published work see [insert ACS Articles on Request author- directed link to Published Work, see http://pubs.acs.org/doi/abs/10.1021/jacs.6b05680

\title{
Tracking the structural and electronic configurations of a cobalt proton reduction catalyst in water
}

Dooshaye Moonshiram, ${ }^{*}, 1, \#$ Carolina Gimbert-Suriñach, ${ }^{* 2, \#}$ Alexander Guda, ${ }^{3}$ Antonio Picon, ${ }^{1}$ C. Stefan Lehmann, ${ }^{1}$ Xiaoyi Zhang, ${ }^{4}$ Gilles Doumy, ${ }^{1}$ Anne Marie March, ${ }^{1}$ Jordi Benet-Buchholz, ${ }^{2}$ Alexander Soldatov, ${ }^{3}$ Antoni Llobet, ${ }^{, 2,5}$ and Stephen H. Southworth ${ }^{1}$

${ }^{1}$ Chemical Sciences and Engineering Division, Argonne National Laboratory, 9700 S. Cass Avenue, Lemont IL 60439, U.S.A

${ }^{2}$ Institute of Chemical Research of Catalonia (ICIQ), Barcelona Institute of Science and Technology, Avinguda Països Catalans 16, 43007 Tarragona, Spain

${ }^{3}$ International Research Center "Smart Materials", Southern Federal University, 344090 Rostov-on-Don, Russia

${ }^{4}$ X-Ray Science Division, Argonne National Laboratory, 9700 S. Cass Avenue, Lemont IL, U.S.A

${ }^{5}$ Departament de Química, Universitat Autònoma de Barcelona, 08193 Cerdanyola del Vallès, Barcelona, Spain

ABSTRACT: Time resolved X-ray absorption spectroscopy (X-TAS) has been used to study the light induced hydrogen evolution reaction catalyzed by a highly stable tetradentate macrocyclic cobalt complex with the formula $\left[\mathrm{LCo}^{\mathrm{III}} \mathrm{Cl}_{2}\right]^{+}(\mathrm{L}=$ macrocyclic ligand), $\left[\mathrm{Ru}(\mathrm{bpy})_{3}\right]^{2+}$ photosensitizer and an equimolar mixture of sodium ascorbate/ascorbic acid electron donor in pure water. XANES and EXAFS analysis of a binary mixture of the octahedral Co(III) pre-catalyst and $\left[\mathrm{Ru}(\mathrm{bpy})_{3}\right]^{2+}$ after illumination, revealed in-situ formation of a Co(II) intermediate with significantly distorted geometry and electron transfer kinetics of $51 \mathrm{~ns}$. On the other hand, X-TAS experiments of the complete photocatalytic system in the presence of the electron donor showed the formation of a square planar Co(I) intermediate species within a few nanoseconds followed by its decay in the microsecond timescales. The Co(I) structural assignment is supported by calculations based on density functional theory (DFT). At longer reaction times, we observe the formation of the initial $\mathrm{Co}$ (III) species concomitant to the decay of $\mathrm{Co}(\mathrm{I})$, thus closing the catalytic cycle. The experimental Xray absorption spectra of the molecular species formed along the catalytic cycle are modeled using a combination of molecular orbital DFT calculations (DFT-MO) and Finite Difference Method (FDM). These findings allowed us to unequivocally assign the full mechanistic pathway followed by the catalyst as well as to determine the rate limiting step of the process, which consists in the protonation of the $\mathrm{Co}(\mathrm{I})$. This study provides a complete kinetics scheme for the hydrogen evolution reaction by a cobalt catalyst, revealing unique information for the development of better catalysts for the reductive side of hydrogen fuel cells.

\section{1-INTRODUCTION}

Solar hydrogen fuel technology based on artificial photosynthesis will only be feasible if it can be performed efficiently and at low cost. ${ }^{1,2}$ From the first report of a functional water splitting cell using UV light as energy source and metallic platinum as a cathode for the hydrogen evolution catalysis, ${ }^{3}$ significant progress has been made towards the construction of cells that use a wider range of the UV-visible-NIR spectrum with increasing solar to hydrogen conversion efficiencies. ${ }^{4}$ They use a variety of configurations taking advantage of photovoltaics and photoelectrochemical technologies or both combined. An important element for the optimum performance and competitive cost of these cells is the hydrogen evolving catalyst (HEC) of the reductive half-cell, responsible for the $\mathrm{H}-\mathrm{H}$ bond formation. While metallic platinum is well known to catalyze the water reduction very efficiently near the thermodynamic potential, the high cost associated with this precious metal has prompted the scientific community to search for alternative catalysts based on earth-abundant materials. In this context, the use of molecular cobalt-based catalysts, stabilized by nitrogen donor ligands, has proven to be a good alternative given the high turnover numbers and stability achieved under catalytic conditions. ${ }^{4-9}$ The catalyst precursor $\left[\mathrm{LCo}^{\mathrm{III}} \mathrm{Cl}_{2}\right]^{+}$( $\mathrm{L}=$ macrocyclic ligand $)$ in Scheme 1 belongs to this family of HEC and has been used in electrochemical as well as photochemical catalysis showing excellent results. ${ }^{10-14}$ In contrast to many other molecular HEC that are active only in organic solvents, complex $\left[\mathrm{LCo}^{\mathrm{III}} \mathrm{Cl}_{2}\right]^{+}$works in pure aqueous conditions showing remarkable stability over a period of several hours. Although mechanistic studies based on electrochemical and spectroscopic methods such as electron paramagnetic resonance or UV-Vis spectroscopy have been re- 
ported, ${ }^{12}$ a full understanding of the reaction pathway for the hydrogen evolution reaction catalyzed by $\left[\mathrm{LCo}^{\mathrm{III}} \mathrm{Cl}_{2}\right]^{+}$has not been described. The main reason for this information gap is the high reactivity of the intermediate species that are involved in the catalysis, with lifetimes in the pico to microsecond timescales. For this reason, time-resolved spectroscopic techniques have become a very powerful tool to track such intermediates. Indeed, pump-probe transient absorption spectroscopy with UV-Vis or IR probes have been successfully used to study the electron transfer process from different photosensitizers such as $\left[\mathrm{Ru}(\mathrm{bpy})_{3}\right]^{2+}$ to $\left[\mathrm{LCo}^{\mathrm{IIII}} \mathrm{Cl}_{2}\right]^{+}$or other cobalt precatalysts. ${ }^{8,14-31}$ With these studies, it was possible to discriminate between oxidative and reductive quenching of the photosensitizers and to trap the Co(I) key intermediate species that triggers the catalysis (Scheme 1). Early reports on mechanistic studies were done with systems that work in organic solvents, using organic acids as proton sources, a media that is unfavorable for a future commercialization of solar cells. More recently, the field has been directed towards the study of catalysts working in pure aqueous conditions, which provide valuable information for a realistic applied catalytic system.

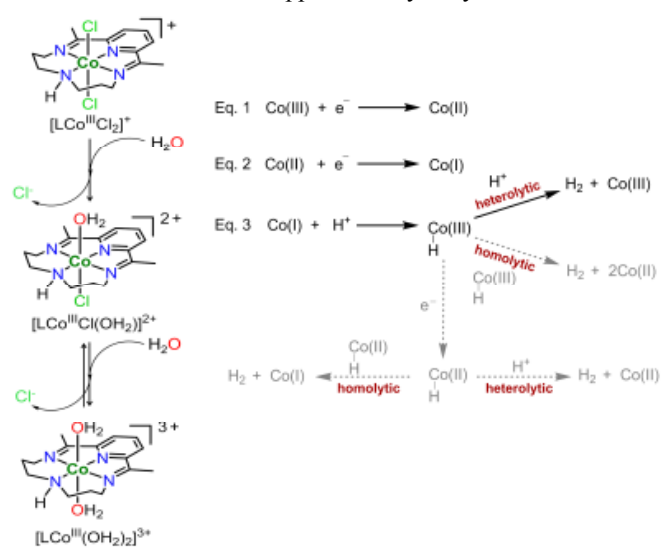

Scheme 1. Left) Cobalt hydrogen evolution catalyst precursor $\left[\mathrm{LCo}^{\mathrm{III}} \mathrm{Cl}_{2}\right]^{+}$studied in this work and its aquated derivatives $\left[\mathrm{LCo}^{\mathrm{III}} \mathrm{Cl}\left(\mathrm{OH}_{2}\right)\right]^{2+}$ and $\left[\mathrm{LCo}^{\mathrm{III}}\left(\mathrm{OH}_{2}\right)_{2}\right]^{3+}$. Right)General scheme of plausible hydrogen evolution pathways from cobalt (I) active species.

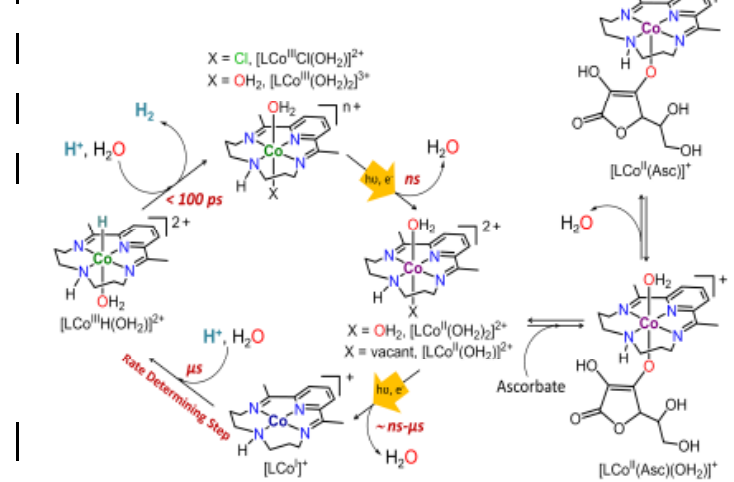

Scheme 2. Mechanistic pathway for the hydrogen evolution reaction catalyzed by $\left[\mathrm{LCo}^{\mathrm{III}} \mathrm{Cl}_{2}\right]^{+}$.

In this work, we use X-ray transient absorption spectroscopy (X-TAS) at the Co K-edge to follow the dynamic processes of a full catalytic cycle for the hydrogen evolution reaction illustrated in Schemes 1 in acidic water. One of the advantages of X-TAS is its element selectivity, allowing us to monitor changes related to cobalt species with no contribution from other components of the system containing ruthenium (from the photosensitizer) or organic compounds. Furthermore, valuable information about oxidation states as well as the coordination sphere around the cobalt center can be extracted, information that is not available using other techniques. XTAS has already been successfully used to study ultrafast electron transfer of multicomponent systems or dyads all the way from the picosecond to the microsecond timescale. ${ }^{22,32-42}$ By combining X-TAS in the ns- $\mu$ s time regime with ab initio theoretical calculations, we were able to characterize intermediate species involved in the catalysis, allowing us to build a complete kinetics, electronic and structural scheme of the reaction. The manuscript is divided according to the sequential processes taking place in the reaction, as illustrated in Scheme 2. Thus, we start by reporting experimental and theoretical XAS simulations of the bis(chloro) $\left[\mathrm{LCo}^{\mathrm{III}} \mathrm{Cl}_{2}\right]^{+}$and bis(aqua) $\left[\mathrm{LCo}^{\mathrm{III}}\left(\mathrm{OH}_{2}\right)_{2}\right]^{3+}$ complexes. We continue with the first electron transfer to convert the $\mathrm{Co}$ (III) initial compound to a reduced $\mathrm{Co}$ (II) intermediate and its interaction with the ascorbate electron donor. Finally, the second electron transfer to form the $\operatorname{Co}(\mathrm{I})$ active species as well as the recovery of the starting $\mathrm{Co}$ (III) derivative, closing the catalytic cycle, is discussed.

\section{2-Results and Discussion}

2-1-Static X-ray absorption spectroscopy analysis of Co(III) pre-catalysts

The bis(chlorido) $\left[\mathrm{LCo}^{\mathrm{III}} \mathrm{Cl}_{2}\right]^{+}$and bis(aqua) $\left[\mathrm{LCo}^{\mathrm{III}}\left(\mathrm{OH}_{2}\right)_{2}\right]^{3+}$ complexes shown in Scheme 1, both in solid and solution form, were studied by X-ray absorption near edge structure (XANES) and Extended X-ray absorption fine structure (EXAFS) spectroscopy (Fig. 1). The substitution of chlorido by aqua axial ligands in these complexes is characterized by a $2.8 \mathrm{eV}$ shift of the rising edge toward higher energy of the XANES spectrum. The large value of the energy shift can be accounted for by ligand to metal charge transfer shakedown transitions. These transitions can affect the energy position ${ }^{43}$ and intensity ${ }^{44}$ of the shoulder on the rising edge of the XANES spectrum upon chlorido to aqua ligand substitution as shown in Kau et $\mathrm{al}^{44}$. This effect has been shown to be especially prominent for complexes with chlorido ligands as compared to those with aqua ligands ${ }^{44}$. The near edge region was simulated with both DFT-MO and FDM methods (Fig. 1 A and Fig. S1). Due to self consistency of the DFT-MO method, it is more accurate in predicting chemical shift for differen oxidation states of Co and XANES in the first $40 \mathrm{eV}$ above absorption edge. This method is not appropriate for higher energy region due to the limited size of the available basis set, consisting of Slater type orbitals. In contrast FDM works well for energies up to $200 \mathrm{eV}$ and more, but this method is inaccurate within $1-2 \mathrm{eV}$ in prediction of the absorption edge energy, thus it is less suitable for the very near edge region of difference spectra discussed below. 
Although the metal center in $\left[\mathrm{LCo}^{\mathrm{III}} \mathrm{Cl}_{2}\right]^{+}$and $\left[\mathrm{LCo}{ }^{\mathrm{III}}\left(\mathrm{OH}_{2}\right)_{2}\right]^{3+}$ has the same formal oxidation state, the calculated Mulliken charge on the Co atom clearly manifest the different crystal field exerted by these two ligands as expected (see Table S2). The shift in energy position of the absorption edge is also attributed to a slight geometrical changes in the $\left[\mathrm{LCo}^{\mathrm{III}} \mathrm{Cl}_{2}\right]^{+}$versus the $\left[\mathrm{LCo}^{\mathrm{III}}\left(\mathrm{OH}_{2}\right)_{2}\right]^{3+}$ complex (compare Co$\mathrm{O}$ and $\mathrm{Co}-\mathrm{Cl}$ distances in Table $\mathrm{S} 1, \mathrm{~S} 2$ ). We further monitored the exchange of the labile chlorido ligands of the $\left[\mathrm{LCo}^{\mathrm{III}} \mathrm{Cl}_{2}\right]^{+}$ complex by aqua ligands in situ, by dissolving the $\left[\mathrm{LCo}^{\mathrm{III}} \mathrm{Cl}_{2}\right]^{+}$ complex in water and taking aliquots that were subsequently frozen at successive time delays from $30 \mathrm{~s}$ to $4 \mathrm{~h}$. A gradual shift in the XANES spectrum confirms partial chlorido to aqua ligand exchange and an eventual equilibrium after $4 \mathrm{~h}$ (Fig. S1 and Scheme 1). The final mixture is composed of an intermediate species with one aqua and one chlorido axial ligands $\left(\left[\mathrm{LCo}^{\mathrm{III}} \mathrm{Cl}\left(\mathrm{OH}_{2}\right)\right]^{2+}\right.$ together with the bis(aqua) complex $\left[\mathrm{LCo}^{\mathrm{III}}\left(\mathrm{OH}_{2}\right)_{2}\right]^{3+}$ as shown in Scheme 1). The isolation of small crystals of $\left[\mathrm{LCo}{ }^{\text {III }} \mathrm{Cl}\left(\mathrm{OH}_{2}\right)\right]^{2+}$ suitable for X-ray single crystal diffraction (XRD) analysis in an aqueous mixture of $\left[\mathrm{LCo}^{\mathrm{III}} \mathrm{Cl}_{2}\right]^{+}$further supports this point- (Table S3). These results are of relevance for the water reduction catalytic experiments that are performed in aqueous conditions and can be extrapolated to a wide range of reported catalysts of similar structure bearing labile chlorido axial ligands, that are generally used as catalyst precursors.
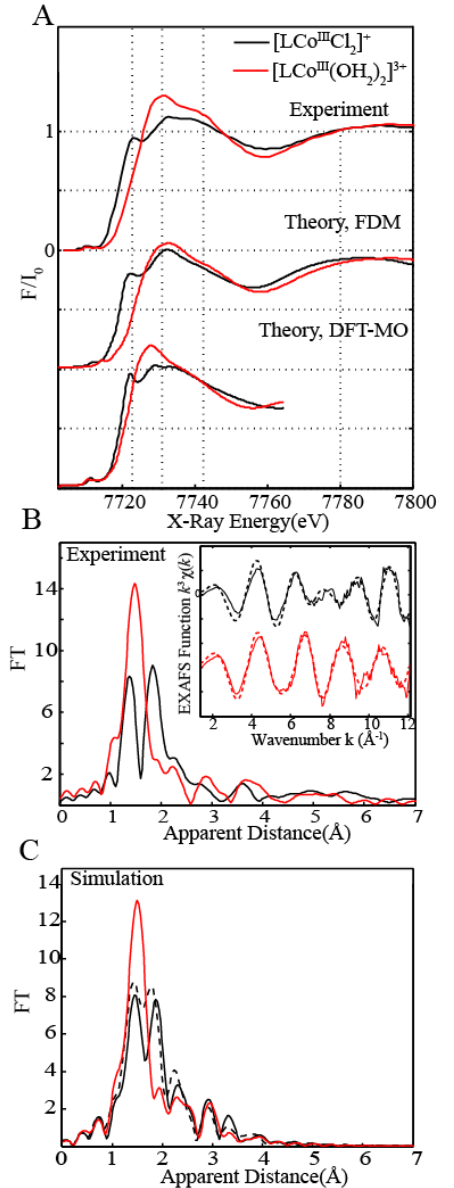

Figure 1. A) Top: Experimental normalized Co K-edge XANES of the $\left[\mathrm{LCo}^{\mathrm{III}} \mathrm{Cl}_{2}\right]^{+}$(black) and $\left[\mathrm{LCo}^{\mathrm{III}}\left(\mathrm{OH}_{2}\right)_{2}\right]^{3+}$ (red) complexes. Bottom: Theoretical XANES simulation using FDM (solid) and DFT-MO (dashed) methods. B) Experimental Fourier transforms of $\mathrm{k}^{3}$-weighted Co EXAFS of the $\left[\mathrm{LCo}^{\mathrm{III}} \mathrm{Cl}_{2}\right]^{+}$(black) and $\left[\mathrm{LCo}^{\mathrm{III}}\left(\mathrm{OH}_{2}\right)_{2}\right]^{3+}$ (red) complexes. Inset: Back Fourier transforms, experimental results (solid lines) and fitting (dashed lines) $\mathrm{k}^{3} \chi(k)$ Experimental spectra were calculated for $\mathrm{k}$ values of 1.431 to $12.103 \AA^{-1}$. C) Simulated EXAFS spectra. Atomic coordinates were obtained from single crystal X-ray diffraction structure of $\left[\mathrm{LCo}^{\mathrm{III}} \mathrm{Cl}_{2}\right]^{+}$(dashed black line) ${ }^{10}$ and from DFT simulations (solid black line for chloro and solid red line for aqua). Note that there is no single crystal X-ray diffraction data for the $\left[\mathrm{LCo}^{\mathrm{III}}\left(\mathrm{OH}_{2}\right)_{2}\right]^{3+}$ sample.

The EXAFS spectra of the bis(chlorido) and bis(aqua) complexes are shown in Fig. 1 B. Two prominent peaks are observed in the $\left[\mathrm{LCo}^{\mathrm{III}} \mathrm{Cl}_{2}\right]^{+}$spectrum corresponding to the distinctive $\mathrm{Co}-\mathrm{N}$ and $\mathrm{Co}-\mathrm{Cl}$ bond distances while only one peak is observed for the $\left[\mathrm{LCo}^{\mathrm{III}}\left(\mathrm{OH}_{2}\right)_{2}\right]^{3+}$ complex with contribution of both the Co-N and Co-O bonds. EXAFS fits for the first coordination sphere and the entire spectrum for both complexes are shown in Table $\mathrm{S} 1$ in the Supporting Information. Analysis of first peak in $\left[\mathrm{LCo}^{\mathrm{III}} \mathrm{Cl}_{2}\right]^{+}$clearly resolves $\mathrm{Co}-\mathrm{N}$ distanc- 
es at $1.89 \AA$, and inclusion of two $\mathrm{Co}-\mathrm{Cl}$ distances at $2.23 \AA$ improves the quality of the fit as shown by the decreased Rfactors and $\chi^{2}$ value (Table S1, Fit 2). Similarly, fitting of $\left[\mathrm{LCo}^{\mathrm{III}}\left(\mathrm{OH}_{2}\right)_{2}\right]^{3+}$ illustrates improvement of the fit quality with the addition of two Co-O distances at $1.93 \AA$ in the first coordination sphere (Table S1, Fit 4). The fitted Co-N and Co-Cl bond distances are in agreement with the reported XRD structure ${ }^{10}$ and relaxed structures from DFT geometry optimization. Changes detected in experimental EXAFS for the $\left[\mathrm{LCo}^{\mathrm{III}} \mathrm{Cl}_{2}\right]^{+}$ and $\left[\mathrm{LCo}^{\mathrm{III}}\left(\mathrm{OH}_{2}\right)_{2}\right]^{3+}$ complexes correlated well with data from XRD analysis and $\mathrm{FEFF}^{45}$ simulations of DFT optimized coordinates (Fig. 1 C). These findings show that theoretical methods including geometry optimization and ab-initio XAS simulations used for $\left[\mathrm{LCo}^{\mathrm{III}} \mathrm{Cl}_{2}\right]^{+}$and $\left[\mathrm{LCo}^{\mathrm{III}}\left(\mathrm{OH}_{2}\right)_{2}\right]^{3+}$ complexes reproduce the experimental data well, and therefore these techniques can be reliably used for analysis of the intermediates species of the cobalt complex's catalytic cycle.

\section{2-2-Time-resolved $X$-ray absorption spectroscopy of bina-} ry mixtures $\mathrm{Ru} / \mathrm{Co}$ : formation of $\mathrm{Co}$ (II)

Formation of the Co(II) intermediate from Co(III) (Eq. 1 in Scheme 1) was probed in the ns- $\mu$ s time range through timeresolved laser/X-ray pump/probe spectroscopy of a water solution mixture consisting of the cobalt catalyst precursor $\left[\mathrm{LCo}^{\mathrm{III}} \mathrm{Cl}_{2}\right]^{+}$with the $\left[\mathrm{Ru}(\mathrm{bpy})_{3}\right]^{2+}$ photosensitizer in 1:5 ratio, that had been incubated for 24 hours allowing for partial chloro ligand substitution. XAS spectra of the binary mixture were collected before (laser off) and after (laser on) the laser excitation. In particular, the laser-on XAS spectrum for an averaged time delay of $918+/-612$ ns between the laser pump excitation and X-ray probing is shown in Fig. 2 A. Upon light excitation, metal-to-ligand charge transfer at the $\left[\mathrm{Ru}(\mathrm{bpy})_{3}\right]^{2+}$ triggers electron transfer from the excited photosensitizer to the Co(III) complex, forming a $\mathrm{Co}$ (II) species. By subtracting the laser-on and laser-off spectrum, a transient signal is obtained for each pump-probe time delay and provides information on the photoinduced dynamics. A transient signal with a maximum timedependent peak energy of $7720 \mathrm{eV}$ is obtained which is typical of the signature of $\mathrm{Co}$ (II) formation (Fig. 3, black trace). We not only observe clear changes in the oxidation state of the Co metal site, but also we see strong changes in the cobalt electronic configuration and coordination environment as indicated by the pre-edge region of the absorption spectrum at lower photon energies around $7710 \mathrm{eV}$ (red trace Fig. 2A, inset). Presence of pre-edge features correspond to $1 \mathrm{~s}$ to $3 \mathrm{~d}$ quadrupole transitions and dipole excitations of the core electrons into the valence $3 \mathrm{~d}$ states hybridized with ligand $\mathrm{p}$ orbitals ${ }^{4,5}$. Non centrosymmetric geometries have been shown to have an increased intensity in their pre-edge features due to an increase in the metal $4 \mathrm{p}$ mixing into the $3 \mathrm{~d}$ orbitals contributing towards the electric dipole $1 \mathrm{~s}$ to $4 \mathrm{p}$ character of this transition as shown in Solomon et $\mathrm{al}^{46-48}$. Octahedral Co(III) complexes have a $\mathrm{d}^{6}$ configuration showing a predominant pre-edge peak $^{46}$. However, local distortions of the octahedron around Co result in additional splitting of the d levels (Figure S4, Supporting Information). Upon laser excitation, the occupation of the Co $d$ shell changes to $d^{7}$, thus enabling a multiplet preedge feature. The d level atomic rearrangements are accompanied with structure relaxation and hybridization of valence $3 \mathrm{~d}$ states with N/O ligand p-orbitals ${ }^{46,47}$. In order to elucidate the structure of the $\mathrm{Co}$ (II) species, three possible geometries of the transient $\mathrm{Co}$ (II) complex were tested by using DFT calculations. A Co(II) octahedral, square pyramidal and square planar geometries were considered depending on the numbers of water molecules coordinated to the cobalt For the calculations presented in figure 3, both the spin polarization contribution shown in Debeer et al. ${ }^{49}$ and the quadrupole transition operator are taken into consideration.

A
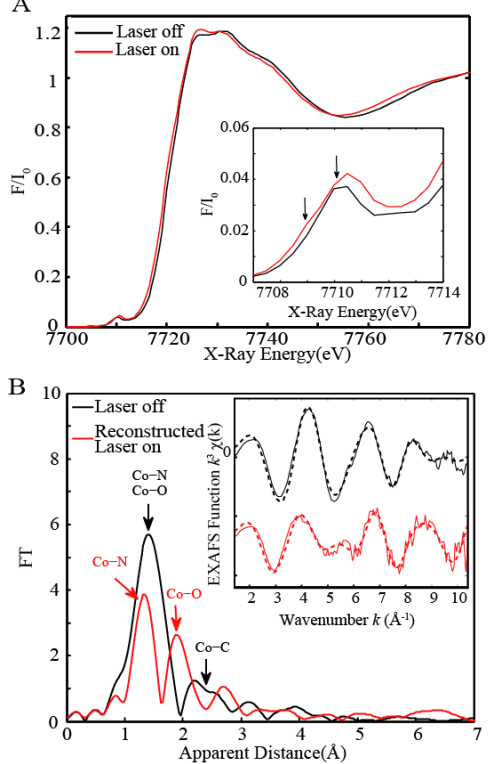

Figure 2. A) Experimental transient $\mathrm{X}$-ray absorption spectrum for the $\left[\mathrm{Ru}(\mathrm{bpy})_{3}\right]^{2+}(30 \mathrm{mM}) /\left[\mathrm{LCo}^{\mathrm{III}} \mathrm{Cl}_{2}\right]^{+}(6 \mathrm{mM})$ binary mixture at the Co K-edge, measured before (black) and an averaged time delay of $918+/-612 \mathrm{~ns}$ after laser excitation. B) Fourier transforms of $\mathrm{k}^{3}$-weighted Co EXAFS of the laser off and reconstructed excited state, considering a $27 \%$ excited state fraction. Inset: Back Fourier transforms, experimental results (solid lines) and fitting (dashed lines) $k^{3} \chi(\mathrm{k})$ Fourier transforms were calculated for $k$ values of 1.431 to $10.358 \AA^{-1}$.

.As shown in Fig. 3, there is poor agreement between experimental spectrum and theoretical simulation for a square planar structure (compare black and blue traces). On the other hand, the simulations for the square pyramidal and distorted octahedral geometries resolve most of the transitions observed in the experimental spectrum including the two pre-edge features (red and pink traces, Fig. 3, inset). However, these preedge transitions as well as the two peaks in the near-edge regions at 7717 and $7727 \mathrm{eV}$ are most prominent in the square pyramidal derivative. The difference in energy for the two preedge transitions was calculated by DFT-MO theory to be around $2 \mathrm{eV}$ for the square pyramidal derivative, comparable to that observed in the experimental pre-edge XAS. Furthermore, analysis of the higher energy region of the spectrum shows that the square pyramidal geometry best describes the position of the maximum peak of the experimental transient spectrum (see Fig. S3). Note that the energy position of calculated transient signal is better when a theoretical "laser off" spectrum from a combination of $\left[\mathrm{LCo}^{\mathrm{III}} \mathrm{Cl}\left(\mathrm{OH}_{2}\right)\right]^{2+}$ and $\left[\mathrm{LCo}^{\mathrm{III}}\left(\mathrm{OH}_{2}\right)_{2}\right]^{3+}$ is considered as opposed to a pure $\left[\mathrm{LCo}^{\mathrm{III}} \mathrm{Cl}_{2}\right]^{+}$or a pure $\left[\mathrm{LCo}^{\mathrm{III}}\left(\mathrm{OH}_{2}\right)_{2}\right]^{3+}$ complex (Fig. S3A and $\mathrm{S} 3 \mathrm{~B}$, respectively). This result is in agreement with an equilibrium between partially substituted $\left[\mathrm{LCo}^{\mathrm{III}} \mathrm{Cl}\left(\mathrm{OH}_{2}\right)\right]^{+}$complex 
and the bis(aqua) $\left[\mathrm{LCo}^{\mathrm{III}}\left(\mathrm{OH}_{2}\right)_{2}\right]^{3+}$ complex as illustrated in Scheme 1.

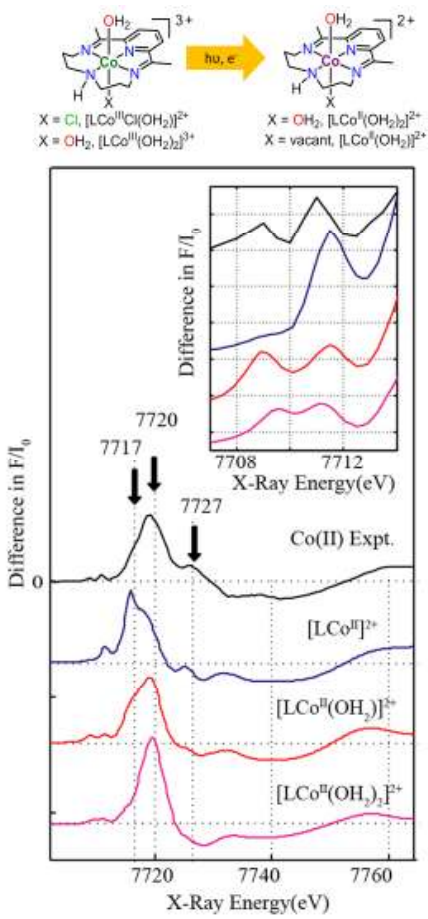

Figure 3. Experimental difference spectrum (laser on-laser off) corresponding to the $\mathrm{Co}$ (II) transient signal (black) and simulated difference spectra for $\left[\mathrm{LCo}^{\mathrm{II}}\right]^{2+}$ square planar (blue), $\left[\mathrm{LCo}^{\mathrm{II}}\left(\mathrm{OH}_{2}\right)\right]^{2+}$ square pyramidal (red) and $\left[\mathrm{LCo}^{\mathrm{II}}\left(\mathrm{OH}_{2}\right)_{2}\right]^{2+}$ octahedral (pink) geometries calculated using DFT-MO method. Molecular orbitals diagrams involved in the transition of the preedge region are illustrated in Figure S4. A 50/50 mixture of $\left[\mathrm{LCo}^{\mathrm{III}} \mathrm{Cl}\left(\mathrm{OH}_{2}\right)\right]^{2+}$ and $\left[\mathrm{LCo}^{\mathrm{III}}\left(\mathrm{OH}_{2}\right)_{2}\right]^{3+}$ was used as theoretical "laser off" spectrum (Scheme 1).

The percentage of the $\mathrm{Co}$ (II) reduced species obtained after laser excitation was determined to be around $27 \%$ by integrating the pre-edge region of the excited state and comparing to a pure $\mathrm{Co}$ (II) sample that was prepared chemically (Fig. S5). Analysis of the reconstructed EXAFS spectrum for the Co(II) photo-induced species reveals two prominent peaks in the first coordination sphere corresponding to the Co-N and the elongated Co-O distances, with values of 1.96 and $2.19 \AA$ respectively (Fig. 2B, Fig S5 D and Table S1). These distances are in agreement with the theoretical relaxed coordinates (see Table S2). In addition, calculated EXAFS profile agrees well with experimental when using these coordinates (Fig. S5 E and Table S2). Note that the Co-O distance is much longer than in the initial $\mathrm{Co}$ (III) complex as expected due to the reduction of the metal site. The presence of an additional peak corresponding to a Co-O distance of $2.19 \AA$ rules out a $\mathrm{Co}$ (II) square planar structure in agreement with the simulations discussed

Importantly, the $\left[\mathrm{LCo}^{\mathrm{III}} \mathrm{Cl}_{2}\right]^{+} /\left[\mathrm{Ru}(\mathrm{bpy})_{3}\right]^{2+}$ system is very stable during time-resolved X-ray absorption measurements over long exposure to X-ray and laser beams at room tempera- ture, as no sample degradation was observed between different scans. This illustrates the robustness of the $\left[\mathrm{LCo}^{\mathrm{III}} \mathrm{Cl}_{2}\right]^{+}$macrocyclic complex as compared to the more commonly used cobaloxime type complexes. ${ }^{50}$ For instance, we carried out time-resolved XAS of a water soluble cobalox$\mathrm{ime} /\left[\mathrm{Ru}(\mathrm{bpy})_{3}\right]^{2+}$ system with the same photon flux and we observed noticeable spectral changes in the XANES features due to the gradual degradation of the initial $\mathrm{Co}(\mathrm{III})$ complex (Fig. S6). In addition, a $\mathrm{Co}(\mathrm{II})$ transient signal analogous to that observed in the $\left[\mathrm{LCo}^{\mathrm{III}} \mathrm{Cl}_{2}\right]^{+} /\left[\mathrm{Ru}(\mathrm{bpy})_{3}\right]^{2+}$ is obtained with other photosensitizers such as water soluble CdTe quantum dots, ${ }^{14}$ confirming the versatility of this catalyst (Fig. S7).

It was possible to measure the kinetics of the formation and decay of the $\mathrm{Co}$ (II) formed in situ by fixing the X-ray photon energy at $7720 \mathrm{eV}$ and varying the time delay between the laser and X-ray pulses. The Co(II) species shows a rise time of $51 \mathrm{~ns}$, consistent with fast electron transfer from the excited photosensitizer to the $\mathrm{Co}$ (III). On the other hand, the decay time of the back electron transfer reaction, responsible for the decay of the Co(II) species was determined to be $5.3 \mu$ s (Fig. 4). These kinetics determine the lifetime of the $\mathrm{Co}(\mathrm{II})$, which should be long lived enough to form the Co(I) active species that enters the catalytic cycle (Eq. 2 and 3, Scheme 1).

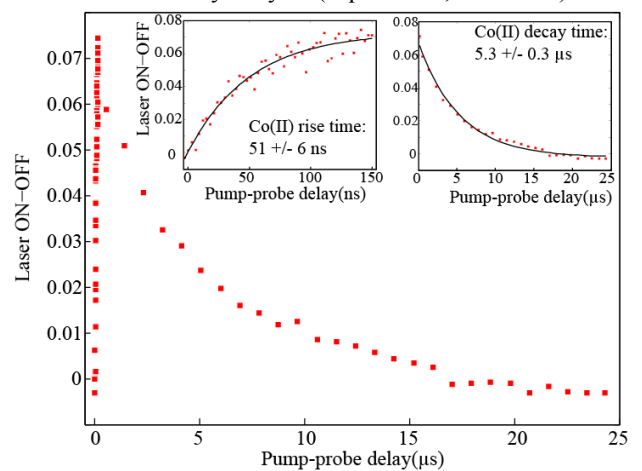

Figure 4. Pump-probe time delay scans recorded at $7720 \mathrm{eV}$ of binary mixture $\left[\mathrm{LCo}^{\mathrm{III}} \mathrm{Cl}_{2}\right]^{+} /\left[\mathrm{Ru}(\mathrm{bpy})_{3}\right]^{2+}$, corresponding to the formation and decay of the $\mathrm{Co}(\mathrm{II})$ photo-induced species. Inset: kinetics fittings of the Co(II) formation (left) and decay (right).

2-3-Interaction of $\mathrm{Co}(\mathrm{II})$ species with ascorbate electron donor

One of the key elements of a homogeneous photochemical HEC system is the sacrificial electron donor that provides the necessary reducing equivalents to produce hydrogen from water. In this study we used ascorbic acid/sodium ascorbate mixtures $\left(\mathrm{H}_{2} \mathrm{Asc} / \mathrm{NaHAsc}, 1: 1\right)$, that have shown excellent results when used in combination with the $\left[\mathrm{LCO}^{\mathrm{III}} \mathrm{Cl}_{2}\right]^{+} /\left[\mathrm{Ru}(\mathrm{bpy})_{3}\right]^{2+}$ hybrid photocatalyst used here. ${ }^{12,31}$ In this system a spontaneous "dark" reduction from $\mathrm{Co}$ (III) to $\mathrm{Co}$ (II) precedes the light-induced hydrogen evolution events due to the reduction potential of the ascorbate agent, that is sufficiently strong to reduce the pre-catalyst $\left[\mathrm{LCo}^{\mathrm{III}} \mathrm{Cl}_{2}\right]^{+}$into a Co(II) derivative. ${ }^{12,14}$ This process is evident from XAS analysis of a mixture of $\left[\mathrm{LCo}^{\mathrm{IIl}} \mathrm{Cl}_{2}\right]^{+}$and $\mathrm{H}_{2} \mathrm{Asc} / \mathrm{NaHAsc}$, showing the expected energy shift in the XANES region when compared with the parent $\mathrm{Co}$ (III) complex. Interestingly, we find that the resulting spectrum for the $\left[\mathrm{LCo}^{\mathrm{III}} \mathrm{Cl}_{2}\right]^{+} /$ascorbate mixture is different to that obtained for a $\mathrm{Co}$ (II) derivative that had 
been prepared in the absence of ascorbate, ${ }^{51}$ suggesting that the ascorbate ion is coordinating the $\mathrm{Co}$ (II) metal site. For instance, comparison of the XANES spectra reveals a $0.4 \mathrm{eV}$ energy shift and a change in the spectral features between the two $\mathrm{Co}$ (II) species (Fig. 5 A). On the other hand, EXAFS analysis of the two Co(II) species illustrates a slight decrease of intensity in the first peak that corresponds to the Co-N bond distance as well as a decrease in the back-scattering amplitude corresponding to the Co-O bond distance (Fig. 5 B), suggesting a change in the first coordination sphere around the cobalt site. The UV-Visible absorption spectrum is also sensitive to the ascorbate coordination to $\mathrm{Co}$ (II) by showing gradual changes in the absorption bands at 350, 460 and $670 \mathrm{~nm}$ (Fig. S9 A).

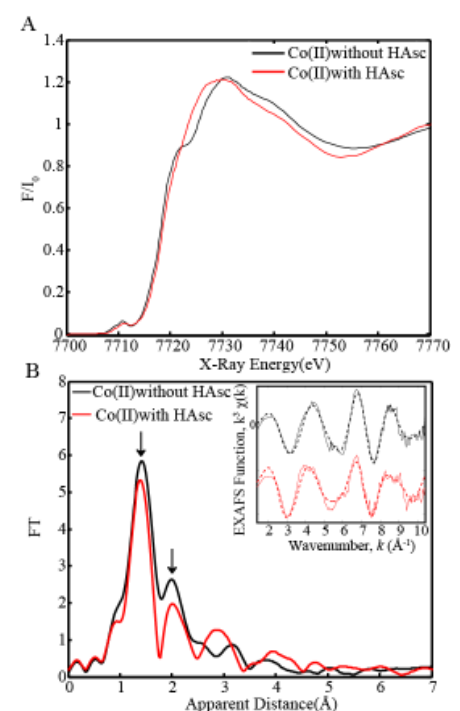

Figure 5. A) Normalized Co K-edge XANES of the Co(II) species $(6 \mathrm{mM})$ prepared chemically in the absence of ascorbate (black) frozen within $5 \mathrm{~min}$, and $\mathrm{Co}(\mathrm{II})$ prepared from the reaction of $\left[\mathrm{LCo}^{\mathrm{III}} \mathrm{Cl}_{2}\right]^{+}(6 \mathrm{mM})$ with ascorbic acid/ascorbate $(200 \mathrm{mM})$ (red) frozen within $4 \mathrm{~h} \mathrm{~B}$ ) Fourier transforms of $\mathrm{k}^{3}$-weighted Co EXAFS of the Co(II) prepared chemically in the absence of ascorbate (black) frozen within $30 \mathrm{~s}$, and $\mathrm{Co}$ (II) prepared from the reaction of $\left[\mathrm{LCo}^{\mathrm{III}} \mathrm{Cl}_{2}\right]^{+}$with ascorbic acid/ascorbate (red) and frozen within 4 hrs. Inset: Back Fourier transforms, experimental results (solid lines) and fitting (dashed lines) $\mathrm{k}^{3} \chi(\mathrm{k})$ Experimental spectra were calculated for $\mathrm{k}$ values of 1.431 to $10.358 \AA^{-1}$.

In order to understand the $\mathrm{Co}(\mathrm{II}) /$ ascorbate interaction, we performed simulation for different structures with ascorbate ion coordination, namely a square pyramidal structure with one ascorbate coordinated ([LCo $\left.\left.{ }^{\mathrm{II}}(\mathrm{Asc})\right]^{+}\right)$and two octahedral complexes with two ascorbate ions $\left.\left(\left[\mathrm{LCo}^{\mathrm{II}}(\mathrm{Asc})_{2}\right)\right]\right)$ or one ascorbate and one water coordinated in the axial positions ([LCo $\left.\left.{ }^{\mathrm{II}}(\mathrm{Asc})\left(\mathrm{OH}_{2}\right)\right]^{+}\right)$(Fig. S2 and Table S2). These calculations reveal that a $\mathrm{Co}$ (II) center with two coordinated ascorbate ions is unstable. On the other hand, XANES simulations show that $\left[\mathrm{LCo}^{\mathrm{II}}(\mathrm{Asc})\left(\mathrm{OH}_{2}\right)\right]^{+}$and $\left[\mathrm{LCo}^{\mathrm{II}}(\mathrm{Asc})\right]^{+}$species both show a shift of the rising edge towards higher energy in agreement with experimental data (Fig. S9 C). In addition, the octahedral derivative $\left[\mathrm{LCo}{ }^{\mathrm{II}}(\mathrm{Asc})\left(\mathrm{OH}_{2}\right)\right]^{+}$features a characteristic shoulder at around $7722 \mathrm{eV}$, resembling the XANES shape obtained for the $\left[\mathrm{LCo}^{\mathrm{III}} \mathrm{Cl}_{2}\right]^{+} /$ascorbate mixture (compare Fig. S9 $\mathrm{B}$ and $\mathrm{C}$ ). These results suggest that an equilibrium between different $\mathrm{Co}$ (II) species with distinct ascorbate coordination exist in the mixture as illustrated in Scheme 2.

\section{4-Time-resolved X-ray absorption spectroscopy of ter- nary mixtures $\mathrm{Ru} / \mathrm{Co} / \mathrm{Asc}$ : formation of $\mathrm{Co}(\mathrm{I})$ and recovery} of Co(III) species

Time-resolved X-ray transient absorption spectroscopy of catalytic mixtures containing the pre-catalyst $\left[\mathrm{LCo}^{\mathrm{III}} \mathrm{Cl}_{2}\right]^{+}(6$ $\mathrm{mM})$, the photosensitizer $\left[\mathrm{Ru}(\mathrm{bpy})_{3}\right]^{2+}(30 \mathrm{mM})$ and the sacrificial electron donor $\mathrm{H}_{2} \mathrm{Asc} / \mathrm{NaHAsc},(1: 1,214 \mathrm{mM})$ in water shows the formation and decay of at least two different cobalt species in the nanosecond to microsecond time scale (Fig. 6) First of all, a reduced species is formed within a few nanoseconds with a maximum peak at $7714 \mathrm{eV}$ in the difference spectrum, suggesting the formation of a $\mathrm{Co}(\mathrm{I})$ derivative. This reduced species has a lifetime of $1.75 \mu \mathrm{s}$ as determined from the kinetics trace obtained at different time delays (Fig. $6 \mathrm{C}$ ). In order to ascertain the structure of this reduced species, XANES spectra of several Co(I) models were simulated and used to calculate the difference spectrum by subtraction with the $\mathrm{Co}$ (II) square pyramidal "laser-off" spectrum $\left(\left[\mathrm{LCo}\left(\mathrm{OH}_{2}\right)\right]^{2+}\right)$. Additional comparison with $\mathrm{Co}(\mathrm{II})$ species with ascorbate coordinated are shown in Fig. S10 in the Supporting Information. Different geometries with different coordinated ligands for a $\mathrm{Co}(\mathrm{I})$ species were considered, namely a square planar, a square pyramidal with an attached water molecule and a square pyramidal with an ascorbate ion in the axial position (Fig. S2 and Table S2). Both low and high spin configurations were calculated for all the $\operatorname{Co}(\mathrm{I})$ models, as it has been suggested that both configurations have similar energies, however no significant differences were found in the respective XANES spectra. ${ }^{52,53}$ As previously mentioned, DFT-MO gives a better description for the pre-edge region, the low energy region below the rising edge, while FDM is preferred to describe the shape of the spectrum in a higher energy range above the edge. Indeed, we observe that the pre-edge peak characteristic of the $\mathrm{Co}(\mathrm{I})$ species at $7714 \mathrm{eV}$ is well reproduced by the DFT-MO simulation of a square planar geometry (red line in Fig. 7 A). The FDM simulated spectra for this geometry also matches well with the high energy range of the experimental spectrum $(>7720 \mathrm{eV})$ (Fig. S10 A) and therefore we conclude that the best agreeable structure for the reduced derivative formed after laser excitation is a Co(I) square planar complex, a geometry that is strongly favored by a $\mathrm{d}^{8}$ electronic configuration. These findings are supported by reported X-ray diffraction structures and calculations of similar intermediates for the $\mathrm{CO}_{2}$ and proton reduction reactions. ${ }^{52,53}$ Since the $\mathrm{Co}$ (II) species slowly interacts with the ascorbate ion with time, the difference spectra considering a "laser-off" $\mathrm{Co}$ (II) square pyramidal with coordinated ascorbate $\left([\mathrm{LCo}(\mathrm{Asc})]^{+}\right)$ are also shown in Figure S10. 

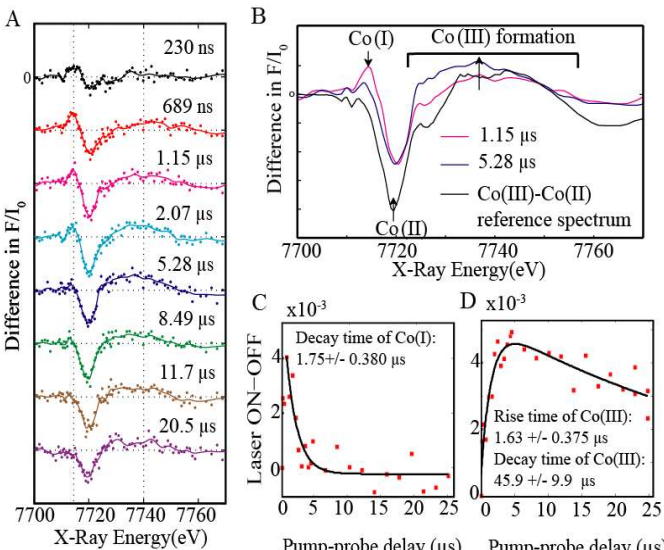

Figure 6. Co K-edge X-ray transient absorption spectra of an aqueous mixture containing $\left[\mathrm{LCo}^{\mathrm{III}} \mathrm{Cl}_{2}\right]^{+}(6 \mathrm{mM}),\left[\mathrm{Ru}(\mathrm{bpy})_{3}\right]^{2+}(30$ $\mathrm{mM})$ and $\mathrm{H}_{2} \mathrm{Asc} / \mathrm{NaHAsc}(1: 1,214 \mathrm{mM})$. A) Stacked spectra corresponding to a series of time delays between laser and X-ray pulses. These measurements were carried out for a range of averaged time delays from 0 to $25 \mu \mathrm{s}$. Each transient signal represents an average of a set of delays over $459 \mathrm{~ns}$. B) Selected transient spectra showing the $\mathrm{Co}(\mathrm{I})$ decay and $\mathrm{Co}(\mathrm{III})$ formation in the 1.15 $\mu$ s (magenta) and $5.28 \mu$ s (blue) time delays. In black, the inverse of the transient spectrum obtained for binary mixtures $\left[\mathrm{LCo}^{\mathrm{III}} \mathrm{Cl}_{2}\right]^{+} /\left[\mathrm{Ru}(\mathrm{bpy})_{3}\right]^{2+}$ corresponding to the $\mathrm{Co}(\mathrm{III})$ to $\mathrm{Co}(\mathrm{II})$ transformation(See black trace in Fig. 3) C) X-ray kinetics taken at $7713.9 \mathrm{eV}$ of a ternary mixture $\left[\mathrm{LCo}^{\mathrm{III}} \mathrm{Cl}_{2}\right]^{+} /\left[\mathrm{Ru}(\mathrm{bpy})_{3}\right]^{2+} / \mathrm{Asc}$, corresponding to the decay of the $\mathrm{Co}(\mathrm{I})$ photo-induced species (red dots) with the corresponding kinetics fitting (black solid line). D) X-ray kinetics taken at $7732.9 \mathrm{eV}$ of a ternary mixture $\left[\mathrm{LCo}^{\mathrm{III}} \mathrm{Cl}_{2}\right]^{+} /\left[\mathrm{Ru}(\mathrm{bpy})_{3}\right]^{2+} /$ Asc, corresponding to the formation and decay of the Co(III) photo-induced species (red dots) with the corresponding kinetics fitting (black solid line). The decay of the $\mathrm{Co}(\mathrm{I})$ species have been fitted using an exponential function. The rise and decay of the Co(III) species have been fitted by using a system of ordinary differential equation with three parameters; the rise rate, the decay rate, and the population of the excited transient Co(I) species.

As the $\operatorname{Co}(\mathrm{I})$ intermediate decays in the measured transient spectra, a second oxidized species is formed, as evidenced by a broad band appearing in the energy range of 7720-7750 eV (Figure 6). The formation of this oxidized species shows a rise time of $1.63 \mu \mathrm{s}$ that correlates well within error bars with the observed Co(I) decay of $1.75 \mu$ s showing that that both processes are linked to the same reaction step (Fig. $6 \mathrm{C}$ and D). According to the different hydrogen evolution pathways considered in Scheme 1, a Co(III) hydride forms after protonation of the $\mathrm{Co}(\mathrm{I})$ intermediate and can generate hydrogen via heterolytic or homolytic pathways by reacting with a proton or a second Co(III) hydride molecule, respectively. Alternatively, it can be reduced to form a $\mathrm{Co}$ (II) hydride species that can analogously react through homolytic or heterolytic mechanisms. Although there is a consensus that the formation of a $\mathrm{Co}$ (III) hydride species is formed after protonation of the $\mathrm{Co}(\mathrm{I})$ intermediate species, little experimental evidence is found in the literature about the steps that follow the formation of this $\mathrm{Co}(\mathrm{I})$ derivative, particularly with systems that work in pure aqueous conditions. ${ }^{30,32-34,54-59}$ Therefore it was of para- mount interest to elucidate the nature of the oxidized species derived from the $\mathrm{Co}(\mathrm{I})$ intermediate generated in our X-TAS experiment. Simulation of XANES spectra of all plausible candidates in Scheme 1, including both $\mathrm{Co}$ (II) and $\mathrm{Co}(\mathrm{III})$ hydride species, were performed and thoroughly analyzed (Fig. S2 and Table S2). Figure 7 B compares the experimental transient spectrum obtained $5.28 \mu$ s after laser excitation with the DFT-MO simulated spectra for three different candidates, namely a $\mathrm{Co}$ (III) octahedral geometry with two water molecules in both axial positions, a $\mathrm{Co}(\mathrm{III})$ hydride square pyramidal complex as well as Co(III) hydride octahedral derivative with an axial water molecule. Additional spectral comparisons of Co(II) hydride species and FDM calculations are found in Fig. S11 in the Supporting Information. The best agreement between experimental and simulated spectra is found for the $\mathrm{Co}(\mathrm{III})$ octahedral geometry with two aqua axial ligands $\left[\mathrm{LCo}^{\mathrm{III}}\left(\mathrm{OH}_{2}\right)_{2}\right]^{3+}$, suggesting that this is the compound formed at longer experimental times (compare red and black traces in Fig. $7 \mathrm{~B}$ and Fig. S11). This hypothesis is confirmed by the good matching of the transient spectrum with the difference spectrum of the isolated compounds $\left[\mathrm{LCo}^{\mathrm{III}}\left(\mathrm{OH}_{2}\right)_{2}\right]^{3+}$ and $\left[\mathrm{LCo}^{\mathrm{II}}\left(\mathrm{OH}_{2}\right)\right]^{+}$or inverting the transient signal shown in Fig. 3 for the binary mixture $\mathrm{Ru} / \mathrm{Co}$ that represents the reverse transition from a $\mathrm{Co}$ (III) to $\mathrm{Co}$ (II) species (compare black and blue lines in Fig. $6 \mathrm{~B}$ )

These findings allowed us to unambiguously-assign the heterolytic pathway through a Co(III) hydride species as the preferred mechanistic route for the hydrogen evolution reaction catalyzed by a derivative of complex $\left[\mathrm{LCo}^{\mathrm{III}} \mathrm{Cl}_{2}\right]^{+}$ (Scheme 2). The rate limiting step of this process is the formation of the intermediate hydride that is so reactive that rapidly combines with a proton in the medium to generate hydrogen gas and recovers the starting complex $\left[\mathrm{LCo}{ }^{\mathrm{III}}\left(\mathrm{OH}_{2}\right)_{2}\right]^{3+}$ within a time scale of less than 2 microseconds. Taking into account the $100 \mathrm{ps}$ pulse duration of the Xrays, we can further affirm that the lifetime of the hydride species is lower than 100 picoseconds. The relatively slow rate (microseconds) associated with the formation of the Co(III) hydride is a consequence of the low reactivity of the $\mathrm{d}^{8} \mathrm{Co}(\mathrm{I})$ square planar intermediate complex that is highly stabilized by the macrocyclic nature of the ligand surrounding the cobalt coordination sphere. Our results suggest that future efforts to enhance the catalytic rate of similar hydrogen evolution catalysts should focus on facilitating the protonation of the $\mathrm{Co}(\mathrm{I})$ intermediate, that is, increasing the basicity of the metal center by either introducing higher electron density to the cobalt or by modifying the stable macrocyclic structure of the ligand Our findings not only prove the mechanistic pathway followed by $\left[\mathrm{LCo}^{\mathrm{III}} \mathrm{Cl}_{2}\right]^{+}$with spectroscopically and kinetically characterized intermediates all along the catalytic cycle, but also confirm the molecular nature of the catalyst, ruling out the formation of zero-valent metallic colloids upon catalytic turnover. 


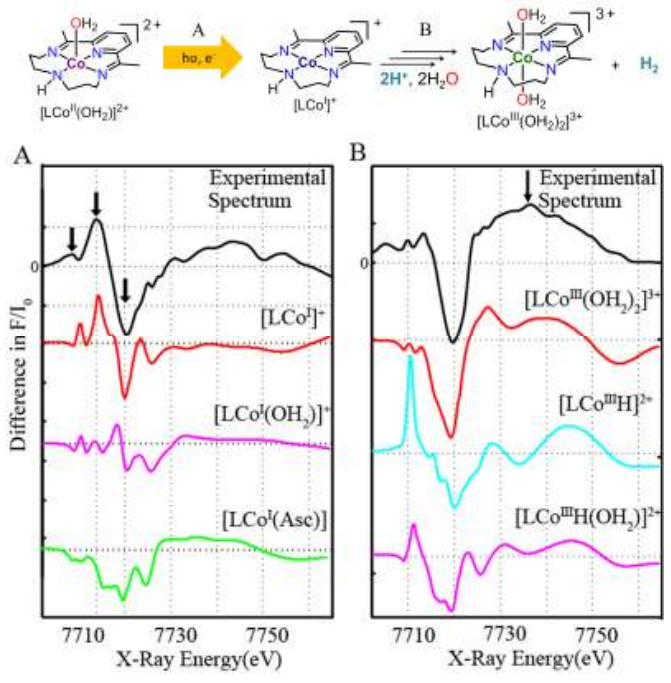

Figure 7. A) Comparison of the experimental difference spectrum taken at an averaged delay of 689+/-230 ns after laser excitation (black) and DFT-MO simulated difference spectra for $\left[\mathrm{LCo}^{\mathrm{I}}\right]^{+}$ square planar (red), $\left[\mathrm{LCo}^{\mathrm{I}}\left(\mathrm{OH}_{2}\right)\right]^{+}$square pyramidal (pink) and $\left[\mathrm{LCo}^{\mathrm{I}}(\mathrm{Asc})\right]^{+}$square pyramidal (green) geometries. B) Comparison of experimental spectrum taken at an averaged delay 5.28+/$0.230 \mu \mathrm{s}$ after laser excitation (black) and DFT-MO simulated difference spectra for $\left[\mathrm{LCo}^{\mathrm{III}}\left(\mathrm{OH}_{2}\right)_{2}\right]^{+}$octahedral (red), $\left.\left[\mathrm{LCo}^{\mathrm{III}} \mathrm{H}\right)\right]^{2+}$ square pyramidal (cyan) and $\left[\mathrm{LCo}^{\mathrm{III}} \mathrm{H}\left(\mathrm{OH}_{2}\right)\right]^{2+}$ octahedral (pink) geometries. The simulated spectrum of a square pyramidal $\mathrm{Co}(\mathrm{II})$ complex with an aqua ligand in the axial position has been used as "laser off" spectrum to calculate the difference spectra in A and B.(See also Fig. S10 and S11 in the supporting information for further comparisons and FDM simulations)

\section{3-Summary and Conclusions}

In summary, we report the application of transient X-ray absorption spectroscopy in combination with DFT calculations in monitoring the electronic and structural dynamics of water soluble $\left[\mathrm{Ru}(\mathrm{bpy})_{3}\right]^{2+} /\left[\mathrm{LCo}^{\mathrm{III}} \mathrm{Cl}_{2}\right]^{+}$hybrid systems. Upon excitation of the chromophore, the cobalt(III) octahedral complex is reduced to a $\mathrm{Co}(\mathrm{II})$ species and undergoes a $\mathrm{Co}-\mathrm{O}$ bond elongation of $0.24 \AA$. We additionally measured the rise time kinetics for the formation of the Co(II) intermediate to be $51 \mathrm{~ns}$ followed by its decay to form the starting Co(III) complex in the order of $5.3 \mu \mathrm{s}$. The study of the complete multimolecular system in the presence of sodium ascorbate/ascorbic acid electron donor $\left(\left[\mathrm{Ru}(\mathrm{bpy})_{3}\right]^{2+} / \mathrm{Co} / \mathrm{Asc}\right)$ shows umbigus experimental proof for the formation of a $\mathrm{Co}(\mathrm{I})$ square planar species followed by the formation of the octahedral $\mathrm{Co}$ (III) starting complex with two axial aqua ligands. The formation of $\mathrm{Co}(\mathrm{I})$ was found to be in the hundreds of nanoseconds time scale while its decay lasts for a few microseconds. The formation of a Co(III) derivative accompanies the decay of the $\mathrm{Co}(\mathrm{I})$ decay, with comparable kinetics in the microsecond timescale. These structural and kinetics results allow us to conclusively determine that the catalyst follows an heterolytic mechanistic pathway where the rate limiting step is the formation of the $\mathrm{Co}$ (III) hydride derivative, which has a lifetime lower than a hundred picoseconds as illustrated in Scheme 2. These findings are crucial to understand the charge separation dynamics in photocatalytic systems for the hydrogen evolution reaction in water and suggest designs of new catalysts that perform beyond the microsecond time regime. They also provide promise for further investigations of light harvester/Co supramolecular assemblies in aqueous medium, where the electron transfer is more efficient through the addition of an electron relay. The electron transfer by the incorporation of a relay is consequently significantly faster in the femtosecond/sub-picosecond timescales. Although sub-ps ultrafast time-resolved studies are not possible at synchrotrons, with temporal resolutions in the 100's picoseconds/nanosecond timescales, development of such types of complexes will provide novel avenues for future studies at free electron lasers where femtosecond time resolution is possible.

\section{4-Experimental Section}

Samples Preparation. Throughout this study, the $\left[\mathrm{LCo}^{\mathrm{III}} \mathrm{Cl}_{2}\right]^{+},\left[\mathrm{LCo}^{\mathrm{III}}\left(\mathrm{OH}_{2}\right)_{2}\right]^{3+}$ and $\left[\mathrm{LCo}^{\mathrm{II}}\left(\mathrm{OH}_{2}\right)\right]^{2+}$ complexes were synthesized as described in the literature. ${ }^{1,12,53}$ Purity of the compounds was verified by ${ }^{1} \mathrm{H}-\mathrm{NMR}$, cyclic voltammetry and/or UV-Vis spectroscopy. Small crystals of [ $\left.\mathrm{LCo}^{\mathrm{III}} \mathrm{Cl}\left(\mathrm{OH}_{2}\right)\right]\left(\mathrm{ClO}_{4}\right)_{2}$ suitable for single crystal XRD analysis were obtained from slow evaporation of an aqueous reaction mixture during the synthesis of $\left[\mathrm{LCo}^{\mathrm{III}}\left(\mathrm{OH}_{2}\right)_{2}\right]\left(\mathrm{ClO}_{4}\right)_{3}$ from $\left[\mathrm{LCo}^{\mathrm{III}} \mathrm{Cl}_{2}\right] \mathrm{Cl}$. The crystals of $\left[\mathrm{LCo}{ }^{\mathrm{III}} \mathrm{Cl}\left(\mathrm{OH}_{2}\right)\right]\left(\mathrm{ClO}_{4}\right)_{2}$ were too small for XAS collection and-XAS analysis. U1trapure (Type 1 ) water (resistivity $18.2 \mathrm{M} \Omega . \mathrm{cm}$ at $25^{\circ} \mathrm{C}$, TOC $4 \mu \mathrm{g} / \mathrm{L}$ ) sourced from a Q-POD unit of Milli-Q integral water purification system (Millipore) was used to prepare the catalytic solutions.

UV-Vis Spectroscopy. A Cary 300 Bio UV-Vis Spectrophotometer (Varian Inc.) was used to monitor UV-visible spectra changes of a solution of $\left[\mathrm{LCo}^{\mathrm{III}} \mathrm{Cl}_{2}\right]^{+}$upon reduction with a mixture of sodium ascorbate and ascorbic acid. UVvisible spectral changes were also monitored for the chloro ligands substitution by aqua for solutions of $\left[\mathrm{LCo}^{\mathrm{III}} \mathrm{Cl}_{2}\right]^{+}$in water

Static XANES and EXAFS Measurements. X-ray absorption spectra were collected at the Advanced Photon Source (APS) at Argonne National Laboratory on bending magnet beamline 20 at electron energy $7.7 \mathrm{keV}$ and average current $100 \mathrm{~mA}$. The radiation was monochromatized by a $\mathrm{Si}(110)$ crystal monochromator. The intensity of the X-ray was monitored by three ion chambers $\left(\mathrm{I}_{0}, \mathrm{I}_{1}\right.$ and $\left.\mathrm{I}_{2}\right)$ filled with $70 \%$ nitrogen and $30 \%$ helium and placed before the sample $\left(\mathrm{I}_{0}\right)$ and after the sample $\left(\mathrm{I}_{1}\right.$ and $\left.\mathrm{I}_{2}\right)$. A Co metal foil was placed between the $I_{1}$ and $I_{2}$ and its absorption recorded with each scan for energy calibration. Plastic (Lexan) EXAFS sample holders (inner dimensions of $12 \mathrm{~mm} \times 3 \mathrm{~mm} \times 3 \mathrm{~mm}$ ) filled with frozen solutions samples were inserted into a precooled $(20 \mathrm{~K})$ cryostat. The samples were kept at $20 \mathrm{~K}$ in a He atmosphere at ambient pressure. Data was recorded as fluorescence excitation spectra using a 13-element energy-resolving detector. Solid samples were diluted with BN powder, pressed between polypropylene and mylar tape, and measured in the cryostat in transmission mode. In order to reduce the risk of sample damage by X-ray radiation, $80 \%$ flux was used in the defocused mode (beam size $1 \times 10 \mathrm{~mm}$ ) and no damage was observed to any samples scan after scan. The samples were also protected from the X-ray beam during spectrometer movements by a shutter synchronized with the scan program. No more than 5 scans were taken at each sample position in any condition. The Co XAS energy was calibrated by the first 
maximum of the second derivative of the cobalt metal XANES spectrum.

Time-resolved XAS measurements. Time-resolved X-ray absorption spectra were collected at 7 ID-D ${ }^{60}$ and 11 ID-D beamlines at the APS using undulator radiation at electron energy $7.7 \mathrm{keV}$. The experiments were carried out using the 24 bunch timing mode of APS (in top up mode with a constant $102 \mathrm{~mA}$ ring current) which consists of a train of xrays separated by $153 \mathrm{~ns}$. This mode easily allows for gateable detectors that selects X-ray pulses. This timing mode was suitable for this type of experiments in which a fresh sample was required for every incoming X-ray pulse as well as for the time resolution of the Avalanche Photodiode (APD)/ fast scintillator detectors.

Experiments carried out at 7 ID-D used an amplified laser system (Duetto from Time-Bandwidth) to generate $10 \mathrm{ps}$ pulses at its second harmonic wavelength of $532 \mathrm{~nm}$. The X-ray beam was focused via Kirkpatrick-Baez optics to around $8 \mu \mathrm{m}$ spot size and overlapped with the laser spatially and temporally. The sample was flown into a free-flowing flat liquid jet sheet with a thickness of $100 \mu \mathrm{m}$ oriented at $45^{\circ}$ to both X-ray and laser beams and continuously degassed with $\mathrm{N}_{2}$ gas. Timeresolved XAS measurements were carried out in fluorescence mode with two fast scintillators positioned at $90^{\circ}$ to the X-ray beam. Laser excitation conditions such as the spot size, repetition rate and power were optimized in order to provide maximum excitation in each probed volume while allowing a fresh sample to be excited from shot to shot. In this case, a laser spot size of $15 \mu \mathrm{m}(\mathrm{V}) \times 11 \mu \mathrm{m}(\mathrm{H})$, repetition rate of $210 \mathrm{kHz}$ and laser power of $138 \mathrm{~mW}$ were used. The $\left[\mathrm{LCo}^{\mathrm{III}} \mathrm{Cl}_{2}\right]^{+}$ complex is very robust, and no degradation was found in the XAS spectra during X-ray and laser irradiation for several hours. In order to monitor the formation of intermediate species in the microsecond time scale, a field programmable gate array logic system was implemented that allowed the collection of data for each of the X-ray pulses in the train between laser pump pulses. With a liquid flow speed of around $6 \mathrm{~m} / \mathrm{s}$ and laser spot size of around $15 \mu \mathrm{m}$, the pumped laser volume moved out of the gaussian full-width-half-maximum (FWHM) probed region in about $1.1 \mu \mathrm{s}$, limiting the temporal range that could be explored. Reducing the flow speed would require a reduction in the pump/probe repetition rate, which is undesirable as more time would be needed to collect the necessary statistics. Instead, a pump-flow-probe scheme was incorporated where the pump beam was spatially separated from the probe position and the flow speed of the sample dictated the pump/probe delay, a variation on the scheme from Smolentev et $\mathrm{al}^{50}$. Such a setup was useful for monitoring the formation of $\mathrm{Co}$ (II) in a binary $\mathrm{Ru} / \mathrm{Co}$ mixture.

Studies of the binary $\mathrm{Ru} / \mathrm{Co}$ mixture and the complete photocatalytic system were additionally repeated at beamline 11 ID-D. The sample was pumped at $527 \mathrm{~nm}$ wavelength using a regenerative amplified laser with $1.6 \mathrm{kHz}$ repetition rate $5 \mathrm{ps}-$ FWHM pulse length and laser power of $630 \mathrm{~mW}$. The sample was flown into a free-flowing $550 \mu \mathrm{m}$ cylindrical jet inside an airtight aluminium chamber and continuously degassed with nitrogen. The X-ray and laser beam was spatially overlapped with an X-ray spot size of $100 \mu \mathrm{m}(\mathrm{V})$ x $450 \mu \mathrm{m}(\mathrm{H})$ and laser spot size of $170 \mu \mathrm{m}(\mathrm{V}) \times 550 \mu \mathrm{m}$. With a liquid flow speed of $3 \mathrm{~m} / \mathrm{s}$, the pumped laser volume was calculated to move out of the gaussian FWHM region in around $24 \mu \mathrm{s}$. This temporal range ensured that the excited state volume was probed more at the center and less at the edges where the excitation fraction would be less, due to movement of the sample. Beamline 11 ID-D has an automated data digitization system which allows for all x-ray pulses after laser excitation to be collected. Such a system, together with the larger X-ray beam spot size, was very useful for our experiments, as multiple X-ray pulses after laser excitation were averaged to monitor the dynamics for the formation and decay of $\mathrm{Co}(\mathrm{II}), \mathrm{Co}(\mathrm{I})$ and $\mathrm{Co}(\mathrm{III})$ transient species in the ns- $\mu$ s time regime. In addition, by averaging multiple pulses, we obtained a better resolution of the main features in the pre-edge and edge regions of the transient signals.

The delay between the laser and X-ray pulses was adjusted by a programmable delay line (PDL-100A-20NS, Colby Instruments) and the X-ray fluorescence signals were collected with two APDs positioned at $90^{\circ}$ on both sides of the liquid jet. Moreover, a combination of Z-1 filters and soller slits with conical geometry were used to reduce the background from elastically scattered x-rays. Note that the kinetics for the formation and decay of the $\mathrm{Co}$ (II) species was measured by varying the delay between the laser and X-ray pulses from $0-25 \mu$ with the programmable delay line. Because of the lower transient signals for the $\mathrm{Co}(\mathrm{I})$ and $\mathrm{Co}(\mathrm{III})$ transient species, their rise and decay kinetics were determined by recording the intensity of the laser (on-off) signal at the peak energy of the transient signal.

At both beamlines 7 ID-D and 11 ID-D, a Co metal foil was placed between two ionization chambers downstream to the $\mathrm{X}$ ray beam, and its transmission recorded with each scan for energy calibration.

EXAFS data analysis. Athena software ${ }^{61}$ was used for data processing. The energy scale for each scan is normalized using the cobalt metal standard and scans made for the same samples were added. Data in energy space are pre-edge corrected, normalized, deglitched (if necessary), and background corrected. The processed data are next converted to the photoelectron wave vector $(k)$ space and weighted by $k^{3}$. The electron wave number is defined as $k=\left[2 m\left(E-E_{0}\right) / \hbar^{2}\right]^{1 / 2}, E_{0}$ is the energy origin or the threshold energy. k-space data were truncated near the zero crossings $\left(\mathrm{k}=1.403\right.$ to $\left.10.358 / 12.103 \AA^{-1}\right)$ in Co EXAFS before Fourier transformation. The k-space data are transferred into the Artemis Software for curve fitting. In order to fit the data, the Fourier peaks are isolated separately, grouped together, or the entire (unfiltered) spectrum was used. The individual Fourier peaks were isolated by applying a Hanning window to the first and last $15 \%$ of the chosen range, leaving the middle $70 \%$ untouched. Curve fitting is performed using $a b$ initio-calculated phases and amplitudes from the FEFF $^{45}$ program and $a b$ initio-calculated phases and amplitudes are used in the EXAFS equation ${ }^{62}$

$$
\chi(k)=S_{0}^{2} \sum_{j} \frac{N_{j}}{k R_{j}^{2}} f_{e f f_{j}}\left(\pi, k, R_{j}\right) e^{-2 \sigma_{j}^{2} k^{2}} e^{\frac{-2 R_{j}}{\lambda_{j}(k)}} \sin \left(2 k R_{j}+\phi_{i j}(k)\right)
$$

where $N_{j}$ is the number of atoms in the $j^{\text {th }}$ shell; $R_{j}$ the mean distance between the absorbing atom and the atoms in the $j^{\text {th }}$ shell; $f_{\text {eff }}\left(\pi, k, R_{j}\right)$ is the ab initio amplitude function for shell $j$, and the Debye-Waller term $e^{-2 \sigma^{2} k^{2}}$ accounts for damping due to static and thermal disorder in absorber-backscatterer distances. The mean free path term $e^{\frac{-2 R_{j}}{\lambda_{j}(k)}}$ reflects losses due to inelastic scattering, where $\lambda_{j}(k)$, is the electron mean free path. 
The oscillations in the EXAFS spectrum are reflected in the sinusoidal term $\sin \left(2 k R_{j}+\phi_{i j}(k)\right)$, where $\phi_{i j}(k)$ is the ab initio phase function for shell $j$. This sinusoidal term shows the direct relation between the frequency of the EXAFS oscillations in k-space and the absorber-back scatterer distance. $S_{0}{ }^{2}$ is an amplitude reduction factor.

The EXAFS equation (Eq. 1) is used to fit the experimental Fourier isolated data ( in q-space) as well as unfiltered data (in $\mathrm{k}$-space) and Fourier transformed data (in R-space) using $N$, $S_{0}^{2}, E_{0}, R$, and $\sigma^{2}$ as variable parameters. $N$ refers to the number of coordination atoms surrounding Co for each shell. The quality of fit is evaluated by R-factor and the reduced $\mathrm{Chi}^{2}$ value. The deviation in $E_{0}$ was required to be less than or equal to $10 \mathrm{eV}$. An R-factor less than $2 \%$ denotes that the fit is good enough whereas an R-factor between 2 and 5\% denotes that the fit is correct within a consistently broad model ${ }^{62}$. The reduced $\mathrm{Chi}^{2}$ value is used to compare fits as more absorberbackscatter shells are included to fit the data. A smaller reduced $\mathrm{Chi}^{2}$ value indicates a better fit. Similar results were obtained from fits done in $\mathrm{k}, \mathrm{q}$, and R-spaces.

DFT-MO and FDM Calculations. The ground state electronic structures and atomic geometries of the different $\mathrm{Co}$ complexes were calculated using DFT B3LYP level of theory using the ADF-2015 program package ${ }^{63}$. There is ongoing discussion in the literature about the best exchange correlation functional ${ }^{64}$ and in our work we tested the popular local GGA-PBE $^{65}$ and hybrid B3LYP ${ }^{66}$ functionals for all cobalt complexes. Both functionals slightly overestimate $\mathrm{Co}-\mathrm{N}$ and Co-ligand bond distances during geometry optimization as compared to the crystallography data. The covalency of metalligand or even metal-metal bonds is strongly affected by the amount of Hartree-Fock exchange in the functional and GGA functionals may overestimate the covalency of bonds while hybrid functionals will give too ionic bonds. The bond length is also affected by the solvent effects which were simulated by means of the COSMO model with a dielectric medium around the molecule. ${ }^{67}$ B3LYP was found to better describe unoccupied molecular orbitals which are subsequently used for XANES calculations, thus in the main text we show results based on this functional. The QZ4P basis set was used in all calculations. Thus each atomic orbital was represented as a combination of four Slater type orbitals (STO) with different exponential powers and 4 polarization functions. STOs are better from a theoretical point of view since they have the correct behavior near the nucleus and the correct asymptotic long-range behavior. Typically, fewer STOs than gaussian GTOs are needed to reach a certain level of accuracy, as discussed in Güell et al. ${ }^{68}$ The X-ray absorption cross section obeys the Fermi golden rule, and the matrix element for the electron transition can be written as

$$
\sigma(E) \sim\left|\left\langle\psi_{f}\left|\boldsymbol{\varepsilon} \cdot \mathbf{r} \cdot e^{i \mathbf{k} \cdot \mathbf{r}}\right| \psi_{1 s}\right\rangle\right|^{2} \cdot \delta\left(E-E_{f}-E_{1 s}\right)
$$

where $\psi_{1 \mathrm{~s}}$ is a core-electron wave function, $\psi_{\mathrm{f}}$ is a wave function for the unoccupied state, $\boldsymbol{\varepsilon}$ is a photon polarization, $\mathbf{k}$ is a photon wavevector. Both dipole and quadrupole terms were taken into account:

$$
\sigma(E) \sim\left|\left\langle\psi_{f}|\boldsymbol{\varepsilon} \cdot \mathbf{r} \cdot(1+i \mathbf{k} \cdot \mathbf{r})| \psi_{1 s}\right\rangle\right|^{2} \cdot \delta\left(E-E_{f}-E_{1 s}\right)
$$

The averaging was performed for all directions of photon polarization and wave vector with a restriction of perpendicu- larity of these two vectors. Calculation of the wave function for unoccupied states is performed using two independen approaches. The first is based on a basis set method within the molecular orbital DFT approach already described above (DFT-MO in the text). Molecular orbitals of the 1s core level and unoccupied levels are used to calculate dipole matrix elements and Lorentzian convolution is subsequently applied for comparison with experiment ${ }^{69}$. In order to represent a final state after the photon absorption process, a core hole is introduced on a 1s cobalt level in a self-consistent way. In a second approach shown in supplemetary we use a finite difference method (FDM in the text) realized in FDMNES software. ${ }^{70}$ In this method, the Schrodinger equation is solved on a $3 \mathrm{~d}$ grid of points and unknowns are the values of the wave function on this grid. The FDM is preferable to describe the shape of the spectrum in a wide energy range but it is less accurate in prediction of absorption edge energy shifts than quantum chemistry DFT-MO approach. Molecular orbitals obtained in a quantum chemistry basis set approach have more accurate energies but fail to describe energy region above $30-40 \mathrm{eV}$ above the absorption edge due to basis set limitations. However in the main text we are interested mainly in the pre-edge region and near edge XAS leaving only DFT-MO in the text for clarity.

For the DFT-MO calculations shown in text, we first obtain eigenvalues and corresponding wavefunctions for spin polarizations for a given Co complex in the presence of a core hole. The matrix elements are then evaluated for transitions between 1s core level and unoccupied MOs using dipole and quadrupole transition operators. In order to compare with experimental results, a convolution of calculated matrix elements was performed with a Lorentzian profile using energy dependent linewidth. In the pre-edge region, the width of the Lorentzian profile corresponds to a core hole lifetime broadening for Co. This value is then increased in higher energy interva with a smooth arctangent function. The parameters of the matrix elements calculations (grid step, size number of unoccupied MOs) and energy convolution are fixed once for al complexes. The DFT-MO calculated spectra were subsequently aligned according to the energy value of the Co $1 \mathrm{~s}$ orbital, thus reproducing the chemical shift for different Co oxidation states. A rigid shift with the identical value of $1 \mathrm{eV}$ was applied for all spectra in order to align the energy scale between experimental data and theoretical calculations.

As mentioned above, it is important to note that metal to ligand charge transfer shakedown transitions can cause a shift in the energy position ${ }^{43}$ and intensity ${ }^{44}$ of the shoulder on the rising edge of the XANES spectrum. However, the proper theoretical description of such state requires the use of multireference computational methods which are at present capable of dealing only with the first several transitions ${ }^{11}$.

In our simulations, we intended to reproduce both pre-edge transitions and main edge features which require calculation of energies and wavefunctions of more than 500 electronic states that were possible only within DFT level of theory. Thus, we expect the discrepancies between energy position of the shakedown transition observed in the experiment and calculated spectra to be in the order of $1 \mathrm{eV}$. However, the effect of the intensity of the peak associated with shakedown transitions is much suppressed for complexes with oxygen bonds ${ }^{44}$.
Field Code Changed

\section{ASSOCIATED CONTENT}


Supporting Information. Additional supporting information is available on EXAFS analysis, XRD data, DFT-MO, and FDM calculations-. This material is available free of charge via the internet at www.//pubs.acs.org

\section{AUTHOR INFORMATION}

\section{Corresponding Authors}

*dmoonshi@gmail.com

*cgimbert@iciq.es

*allobet@iciq.es

\section{Author Contributions}

$\$$ These authors contributed equally.

\section{ACKNOWLEDGMENT}

We acknowledge support from the U.S. Department of Energy, Office of Science, Basic Energy Sciences, Chemical Sciences, Geosciences, and Biosciences Division under contract no. DEAC02-06CH1 1357. This research uses resources of the Advanced Photon Source(APS), a U.S Department of Energy (DOE) Office of Science User Facility operated for the DOE Office of Science by Argonne National Laboratory under Contract No. DE-AC0206CH11357. We thank Dr. Chengjun Sun and Dr. Qingyu Kong for help with experiments at beamlines $20 \mathrm{BM}$ and 11 ID-D, APS. We also acknowledge financial support from MINECO and the "Fondo Europeo de Desarrollo Regional" (FEDER) through grants CTQ-2013-49075-R, SEV-2013-0319, and CTQ-201452974-REDC. Financial support from the EU COST actions CM1202 and CM1205 are also acknowledged. C.G.S. is grateful to AGAUR and Generalitat de Catalunya for a "Beatriu de Pinós" postdoctoral grant. A.G. and A.S. would like to thank the Russian Ministry of Education and Science for the support (agreement № 14.587.21.0002, unique identifier RFMEFI58714X0002).

\section{REFERENCES}

(1) Walter, M. G.; Warren, E. L.; McKone, J. R.; Boettcher, S. W.; Mi, Q.; Santori, E. A.; Lewis, N. S. Chem.Rev. 2010, 110, 6446. (2) McKone, J. R.; Lewis, N. S.; Gray, H. B. Chem.Mat. 2014, 26, 407.

(3) Fujishima, A.; Honda, K. Nature 1972, 238, 37.

(4) Queyriaux, N.; Jane, R. T.; Massin, J.; Artero, V; ChavarotKerlidou, M. Coord. Chem. Rev. 2015, 304-305, 3.

(5) Eckenhoff, W. T.; Eisenberg, R. Dalton. Trans. 2012, 41, 13004. (6) Thoi, V. S.; Sun, Y.; Long, J. R.; Chang, C. J. Chem. Soc. Rev. 2013, 42, 2388

(7) Berardi, S.; Drouet, S.; Francas, L.; Gimbert-Surinach, C.; Guttentag, M.; Richmond, C.; Stoll, T.; Llobet, A. Chem. Soc. Rev. 2014, 43, 7501.

(8) Khnayzer, R. S.; Thoi, V. S.; Nippe, M.; King, A. E.; Jurss, J. W.; El Roz, K. A.; Long, J. R.; Chang, C. J.; Castellano, F. N. Energy Environ.Sci. 2014, 7, 1477.

(9) Tong, L.; Kopecky, A.; Zong, R.; Gagnon, K. J.; Ahlquist, M. S. G.; Thummel, R. P. Inorg.Chem. 2015, 54, 7873.

(10) Leung, C.-F.; Chen, Y.-Z.; Yu, H.-Q.; Yiu, S.-M.; Ko, C.-C.; Lau, T.-C. Int. J.-Hydrogen Energy 2011, 36, 11640.

(11) McCrory, C. C. L.; Uyeda, C.; Peters, J. C. J.Am.Chem.Soc. 2012, 134, 3164.

(12) Varma, S.; Castillo, C. E.; Stoll, T.; Fortage, J.; Blackman, A. G.; Molton, F.; Deronzier, A.; Collomb, M.-N. Phys.Chem.Chem.Phys. 2013, 15,17544 .

(13) Roy, S.; Bacchi, M.; Berggren, G.; Artero, V. ChemSusChem 2015, $8,3632-3638$

(14) Gimbert-Suriñach, C.; Albero, J.; Stoll, T.; Fortage, J.; Collomb, M.-N.; Deronzier, A.; Palomares, E.; Llobet, A. J.Am.Chem.Soc. 2014, 136, 7655 .

(15) Natali, M.; Orlandi, M.; Chiorboli, C.; Iengo, E.; Bertolasi, V.; Scandola, F. Photochem.Photobiol.Sci. 2013, 12, 1749 .
(16) Dong, J.; Wang, M.; Zhang, P.; Yang, S.; Liu, J.; Li, X.; Sun, L. J. Phys. Chem C 2011, 115, 15089.

(17) Shan, B.; Baine, T.; Ma, X. A. N.; Zhao, X.; Schmehl, R. H. Inorg. Chem. 2013, 52, 4853

(18) Lewandowska-Andralojc, A.; Baine, T.; Zhao, X.; Muckerman, J. T.; Fujita, E.; Polyansky, D. E. Inorg. Chem. 2015, 54, 4310. (19) Rodenberg, A.; Orazietti, M.; Probst, B.; Bachmann, C.; Alberto, R.; Baldridge, K. K.; Hamm, P. Inorg. Chem. 2015, 54, 646.

(20) Cropek, D. M.; Metz, A.; Muller, A. M.; Gray, H. B.; Horne, T. Horton, D. C.; Poluektov, O.; Tiede, D. M.; Weber, R. T.; Jarrett, W. L.; Phillips, J. D.; Holder, A. A. Dalton Trans. 2012, 41, 13060.

(21) Veldkamp, B. S.; Han, W.-S.; Dyar, S. M.; Eaton, S. W.; Ratner, M. A.; Wasielewski, M. R. Energy Environ.Sci. 2013, 6, 1917.

(22) Mukherjee, A.; Kokhan, O.; Huang, J.; Niklas, J.; Chen, L. X.; Tiede, D. M.; Mulfort, K. L. Phys.Chem.Chem.Phys. 2013, 15, 21070. (23) Huang, J.; Mulfort, K. L.; Du, P.; Chen, L. X. J.Am.Chem.Soc 2012, 134, 16472.

(24) Guttentag, M.; Rodenberg, A.; Kopelent, R.; Probst, B.; Buchwalder, C.; Brandstätter, M.; Hamm, P.; Alberto, R. Eur. J. Inorg. Chem. 2012, 2012, 1,59

(25) Reynal, A.; Lakadamyali, F.; Gross, M. A.; Reisner, E.; Durrant, J. R. Energy Environ.Sci. 2013, 6, 3291.

(26) Lakadamyali, F.; Reynal, A.; Kato, M.; Durrant, J. R.; Reisner, E. Chem. Eur. J. 2012, 18, 15464

(27) Reynal, A.; Willkomm, J.; Muresan, N. M.; Lakadamyali, F.; Planells, M.; Reisner, E.; Durrant, J. R. Chemical Communications 2014, 50,12768

(28) Soltau, S. R.; Niklas, J.; Dahlberg, P. D.; Poluektov, O. G.; Tiede, D. M.; Mulfort, K. L.; Utschig, L. M. Chem. Commun. 2015 $51,10628$.

(29) Deponti, E.; Luisa, A.; Natali, M.; Iengo, E.; Scandola, F. Dalton Trans. 2014, 43, 16345 .

(30) Dempsey, J. L.; Winkler, J. R.; Gray, H. B. J.Am.Chem.Soc 2010, $132,16774$.

(31) Gueret, R.; Castillo, C. E.; Rebarz, M.; Thomas, F.; Hargrove, A.-A.; Pécaut, J.; Sliwa, M.; Fortage, J.; Collomb, M.-N. J J. Photochem. Photobiol. B, Biol. 2015, 152, Part A, 82 .

(32) Smolentsev, G.; Guda, A.; Zhang, X.; Haldrup, K.; Andreiadis, E. S.; Chavarot-Kerlidou, M.; Canton, S. E.; Nachtegaal, M.; Artero, V.; Sundstrom, V. J.Phys.Chem.C 2013, 117, 17367.

(33) Smolentsev, G.; Guda, A. A.; Janousch, M.; Frieh, C.; Jud, G.; Zamponi, F.; Chavarot-Kerlidou, M.; Artero, V.; van Bokhoven, J. A.; Nachtegaal, M. Farad. Discuss. 2014, 171, 259.

(34) Smolentsev, G.; Cecconi, B.; Guda, A.; Chavarot-Kerlidou, M. van Bokhoven, J. A.; Nachtegaal, M.; Artero, V. Chem. Eur. J. 2015, 21,15158 .

(35) Chen, L. X.; Zhang, X.; Lockard, J. V.; Stickrath, A. B.; Attenkofer, K.; Jennings, G.; Liu, D.- -J. Acta Crystallogr. Sect. A 2010, 66, 240 .

(36) Smolentsev, G.; Canton, S. E.; Lockard, J. V.; Sundstrom, V.; Chen, L. X. J. Electron. Spectrosc. Relat. Phenom. 2011, 184, 125.

(37) Chen, L. X.; Zhang, X. J.Phys.Chem.Lett. 2013, 4, 4000

(38) Canton, S. E.; Zhang, X.; Zhang, J.; van Driel, T. B.; Kjaer, K S.; Haldrup, K.; Chabera, P.; Harlang, T.; Suarez-Alcantara, K.; Liu, Y.; Pérez, J.; Bordage, A.; Pápai, M.; Vankó, G.; Jennings, G.; Kurtz, C. A.; Rovezzi, M.; Glatzel, P.; Smolentsev, G.; Uhlig, J.; Dohn, A O.; Christensen, M.; Galler, A.; Gawelda, W.; Bressler, C.; Lemke, H. T.; Møller, K. B.; Nielsen, M. M.; Lomoth, R.; Wärnmark, K.; Sundström, V. J.Phys.Chem.Lett. 2013, 4, 1972.

(39) Chen, L. X.; Zhang, X.; Shelby, M. L. Chem.Sci. 2014, 5, 4136. (40) Canton, S. E.; Kjær, K. S.; Vankó, G.; van Driel, T. B.; Adachi, S.-i.; Bordage, A.; Bressler, C.; Chabera, P.; Christensen, M.; Dohn, A. O.; Galler, A.; Gawelda, W.; Gosztola, D.; Haldrup, K.; Harlang, T.; Liu, Y.; Møller, K. B.; Németh, Z.; Nozawa, S.; Pápai, M.; Sato, T.; Sato, T.; Suarez-Alcantara, K.; Togashi, T.; Tono, K.; Uhlig, J.; Vithanage, D. A.; Wärnmark, K ; Yabashi, M.; Zhang, J.; Sundström, V.; Nielsen, M. M. Nat. Commun 2015, 6,1

(41) Smolentsev, G.; Sundström, V. Coord.Chem.Rev. 2015, 304 305,117

(42) Mulfort, K. L.; Mukherjee, A.; Kokhan, O.; Du, P.; Tiede, D. M. Chem.Soc.Rev. 2013, 42, 2215. 
(43) Bair, R. A.; Goddard, W. A. Phys.Rev.B. 1980, 22, 2767. (44) Kau, L. S.; Spira-Solomon, D. J.; Penner-Hahn, J. E.; Hodgson, K. O.; Solomon, E. I. J. Am. Chem. Soc. 1987, 109, 6433.

(45) Rehr, J. J.; Albers, R. C. Rev. Mod. Phys. 2000, 72, 621.

(46) Westre, T. E.; Kennepohl, P.; DeWitt, J. G.; Hedman, B.; Hodgson, K. O.; Solomon, E. I. J. Am. Chem. Soc. 1997, 119, 6297.

(47) Loeb, K. E.; Westre, T. E.; Kappock, T. J.; Mitic, N.; Glasfeld, E.; Caradonna, J. P.; Hedman, B.; Hodgson, K. O.; Solomon, E. I. J. Am. Chem. Soc. 1997, 119, 1901

(48) Hahn, J. E.; Scott, R. A.; Hodgson, K. O.; Doniach, S.; Desjardins, S. R.; Solomon, E. I. Chem. Phys. Lett. 1982, 88, 595. (49) Chandrasekaran, P.; Stieber, S. C. E.; Collins, T. J.; Que, J. L.; Neese, F.; DeBeer, S. Dalton Trans. 2011, 40, 11070.

(50) Smolentsev, G.; Guda, A.; Zhang, X.; Haldrup, K.; Andreiadis, E. S.; Chavorot-Kerlidou, M.; Canton, S. E.; Nachtegaal, M.; Artero, V.; Sundstrom, V. J.Phys. Chem.C 2013, 117, 17367.

(51) Long, K. M.; Busch, D. H. Inorg. Chem.1970, 9, 505.

(52) Lacy, D. C.; McCrory, C. C. L.; Peters, J. C. Inorg. Chem. 2014, 53,4980 .

(53) Zhang, M.; El-Roz, M.; Frei, H.; Mendoza-Cortes, J. L.; HeadGordon, M.; Lacy, D. C.; Peters, J. C. J. Phys. Chem. C 2015, 119, 4645 .

(54) Hu, X.; Brunschwig, B. S.; Peters, J. C. J.Am.Chem.Soc. 2007, 129,8988 .

(55) Muckerman, J. T.; Fujita, E. Chem.Commun. 2011, 47, 12456.

(56) Solis, B. H.; Hammes-Schiffer, S. J.Am.Chem.Soc. 2011, 133, 19036 .

(57) Bhattacharjee, A.; Weiss, A. K. H.; Artero, V.; Field, M. J.; Hofer, T. S. J.Phys.Chem.B. 2014, 118, 5551.

(58) Niklas, J.; Mardis, K. L.; Rakhimov, R. R.; Mulfort, K. L.; Tiede, D. M.; Poluektov, O. G. J.Phys.Chem.B. 2012, 116, 2943.

(59) Estes, D. P.; Grills, D. C.; Norton, J. R. J.Am.Chem.Soc. 2014, $136,17362$.

(60) March, A. M.; Stickrath, A.; Doumy, G.; Kanter, E. P.; Krassig, B.; Southworth, S. H.; Attenkofer, K.; Kurtz, C. A.; Chen, L. X.; Young, L. Rev.Sci.Instrum. 2011, 82, 073110.

(61) Ravel, B.; Newville, M. J. Synchrotron Radiat. 2005, 12, 537.

(62) Koningsberger, D. C.; Prins, R. X Ray Absorption: Principles, Applications, Techniques of EXAFS, SEXAFS and XANES; John Wiley \& Sons, 1988

(63) Guerra, C. F.; Snijders, J. G.; te Velde, G.; Baerends, E. J. Theor. Chem. Acc. 1998, 99, 391.

(64) Cramer, C. J.; Truhlar, D. G. Phys.Chem.Chem.Phys 2009, 11, 10757.

(65) Perdew, J. P.; Burke, K.; Ernzerhof, M. Phy.Rev.Lett. 1996, 77, 3865

(66) Reiher, M.; Salomon, O.; Artur Hess, B. Theor.Chem.Acc., 107, 48.

(67) Klamt, A.; Schuurmann, G. J. Chem. Soc., Perkin Trans. 2, 1993, 799

(68) Güell, M.; Luis, J. M.; Solà, M.; Swart, M. J.Phys.Chem.A. 2008, 112,6384 .

(69) Alperovich, I.; Smolentsev, G.; Moonshiram, D.; Jurss, J. W.; Concepcion, J. J.; Meyer, T.; Soldatov, A.; Pushkar, Y. J .Am. Chem. Soc. 2001, 133,15786

(70) Guda, S. A.; Guda, A. A.; Soldatov, M. A.; Lomachenko, K. A.; Bugaev, A. L.; Lamberti, C.; Gawelda, W.; Bressler, C.; Smolentsev, G.; Soldatov, A. V.; Joly, Y. J. Chem. Theory Comput. 2015, 11, 4512.

(71) Tomson, N. C.; Williams, K. D.; Dai, X.; Sproules, S.; DeBeer,

S.; Warren, T. H.; Wieghardt, K. Chem. Sci.2015, 6, 2474. 


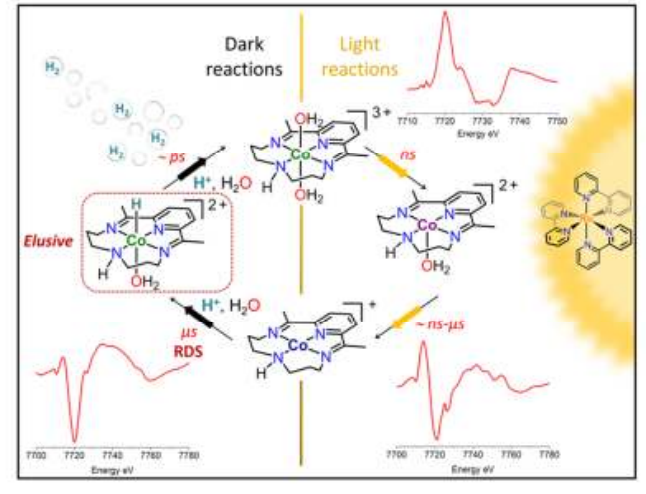

